\title{
Clinical profile and etiogical spectrum of patients with acute kidney injury at a tertiary care hospital
}

\author{
N S Deshpande ${ }^{1 *}$, Jugal Harkut ${ }^{2}$
}

${ }^{1}$ Professor \& HOD, Department of Medicine, 2Junior Resident, Vilasrao Deshmukh Institute of Medical Sciences, Latur, Maharashtra, INDIA Email: drneelima08@gmail.com, jugalkishorehrkt@gmail.com

\begin{abstract}
Background: Acute kidney injury is the major causes of preventable morbidity and mortality worldwide. We conducted an observational single-centre study from January 2018 to June 2019, with 170 patients. Aim and Objectives: The goal of this study was to organize the clinical presentation of Acute kidney injury patients and to survey the clinical presentation of Acute kidney injury in regard to its fluctuated etiologies. Material and Methods: In this study age more than 12 years and patients admitted to Medicine ward and Intensive care unit with Acute Kidney Injury were enrolled. Diabetic nephropathy, diagnosed case of chronic kidney disease, surgical cases not included in this study. After written consent, detail history was taken of all the selected patients. Detail clinical examination conducted and the findings were recorded on a prestructured proforma sheet. Result: Out of 170, 112 were males and 58 were females. In this study we noticed that decreased urine output, swelling over face and lower limb and vomiting was most common presenting symptoms comprising of $44 \%, 45 \%$ and $34 \%$ respectively. The common aetiologies were acute gastroenteritis $(20 \%)$, snake and unknown bite (18.8\%), Infective causes (15.8\%) and Poisoning and drug induced (15.2\%). Conclusion: Decreased urine output, swelling over face and lower limb and vomiting were common presentation of Acute Kidney Injury in this study. Highest incidence of Acute Kidney Injury was attributed to medical disorders consisting of mainly septicemia, acute gastroenteritis, multiple organ dysfunction syndrome, snake bite and Nephrotoxic drugs.

Key Words: ACUTE KIDNEY INJURY, KDIGO CLASSIFICATION INTRODUCTION
\end{abstract}

*Address for Correspondence:

Dr N.S. Deshpande, Professor \& HOD, Department of Department, Vilasrao Deshmukh Institute of Medical Sciences, Latur, Maharashtra, INDIA.

Email: drneelima08@gmail.com

Received Date: 24/04/2020 Revised Date: 29/05/2020 Accepted Date: 28/07/2020

DOI: https://doi.org/10.26611/10211532

This work is licensed under a Creative Commons Attribution-NonCommercial 4.0 International License. $(\mathbf{c c})$ EY-NC

\begin{tabular}{|l|l|}
\hline \multicolumn{2}{|c|}{ Access this article online } \\
\hline Quick Response Code: & Website: \\
\hline & www.medpulse.in \\
& \\
\hline
\end{tabular}

\section{INTRODUCTION}

Acute kidney injury depicts the abrupt decline in nephritic perform principally essentially occurs over the course (hours to days) and ends in retention of metabolic waste products and dysregulation of fluid, electrolytes, and acid base physiological state ${ }^{1}$. According to Kidney Disease Improving Global Outcomes (KDIGO) 2012-Acute kidney injury (AKI) is defined by presence of any one of the followings $\mathrm{s}^{2,3}$.

1. Increase in serum creatinine by $\geq 0.3 \mathrm{mg} / \mathrm{dl}$ $(\geq 26.5 \mu \mathrm{mol} / 1)$ within 48 hours.

2. Increase in serum creatinine to $\geq 1.5$ time's baseline which is known or presumed to have occurred within the previous seven days.

3. Urine volume $<0.5 \mathrm{ml} / \mathrm{kg} / \mathrm{hr}$ for more than six hours.

Acute Kidney Injury is associated with high morbidity and mortality. So early identifying and early treatment to avoid renal replacement therapy and associated complications. 


\section{MATERIAL AND METHODS}

This study was conducted in department of medicine, Vilasrao Deshmukh Government Institute of Medical Sciences, Latur. The study was an observational singlecentre study conducted from January 2018 to June 2019, with 170 patients to characterize Acute Kidney Injury, defined by KDIGO classification. Following inclusion and exclusion criteria was used to select the study subjects.

\section{INCLUSION CRITERIA:}

1. Increase in serum creatinine by $\geq 0.3 \mathrm{mg} / \mathrm{dl}$ $(\geq 26.5 \mu \mathrm{mol} / 1)$ within 48 hours.

2. Increase in serum creatinine to $\geq 1.5$ time's baseline which is known or presumed to have occurred within the previous seven days.

3. Urine volume $<0.5 \mathrm{ml} / \mathrm{kg} / \mathrm{hr}$ for more than six hours.

4. Age group: More than 12 Years

\section{EXCLUSION CRITERIA:}

1. Trauma and accidental case

2. Patients with diabetes mellitus

3. Patients with Chronic kidney disease

After written consent, detail history was taken of all the selected study patients. Detail clinical examination conducted and the findings were recorded on a prestructured proforma sheet. We calculated the mean \pm standard deviations $(\mathrm{x} \pm \mathrm{s})$ or the medians for continuous variables and proportion of categorical variables. T-test was used to compare the continuous variables of normal Distributions and Rank sum test was utilised for the continuous variables with abnormal distributions. Chisquare test was employed to compare categorical variable data. $\mathrm{P}$ value $<0.05$ was considered significant. The Independent Samples $\mathrm{T}$ Test was used to compare the means of two independent groups in order to determine whether there was statistical evidence that the associated population means were significantly different. Data were analysed using SPSS11.5 software.

\section{RESULTS}

\section{GENDER DISTRIBUTION-}

Out of 170,112 were males and 58 were females with a mean age of 51.76 years with SD of 18.68. In this study male: female ratio was $2: 1$. Male $(66 \%)$ sex was predominantly affected in this study. Sex difference doesn't show any significant difference in the outcome.

\section{AGE DISTRIBUTION}

In this study group most of them fall with in age limit of more than 60years, Mean age group is 51.76 years with standard deviation of 18.68 years. Minimum age group in this study is 13 years and maximum age group in this study is 86 years.

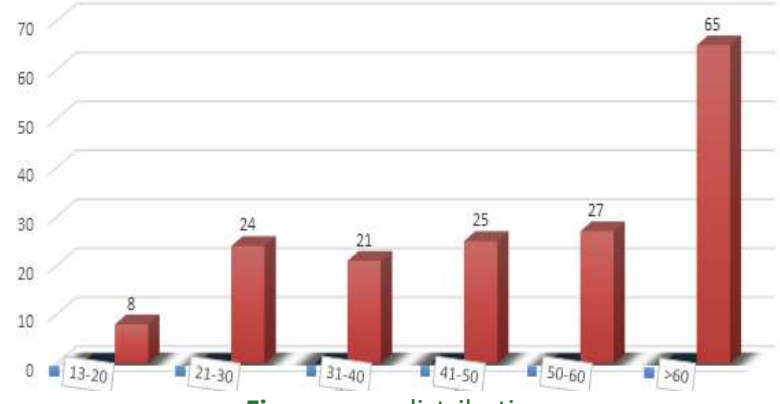

Figure : age distribution

Most commonly affected age group in this study was more than 60 years $(38.23 \%)$ followed by $50-60$ years $(15.88 \%)$. Least affected age group in this study was 13-20 years $(4.7 \%)$.

\section{CLINICAL SYMPTOMATOLOGY}

All 170 patients divided according to common presenting symptoms. We noticed that decrease urine output, swelling over feet and face and vomiting was most common presenting symptoms comprising of $44 \%, 45 \%$ and $34 \%$ respectively.
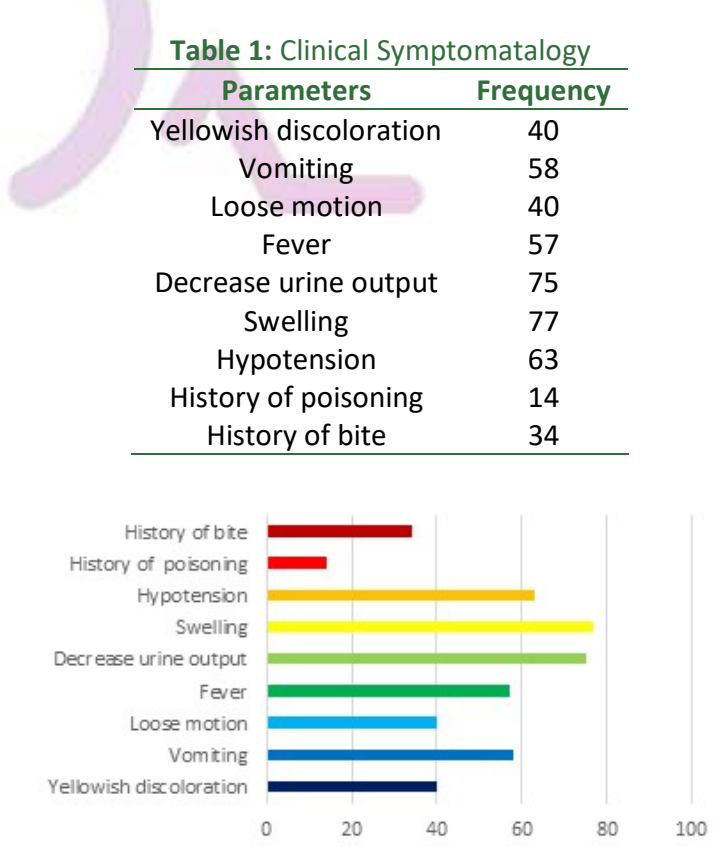

Figure 1: Frequency of clinical symptomatology

This graphical representation shows different clinical presentation of Acute Kidney Injury. Almost $44.11 \%$ of them had decreased urine output as a significant complaint. In our part of the country acute gastroenteritis also contributes to most patients of acute kidney injury. 
Table 2: Causes of pre-renal acute kidney injury

\begin{tabular}{|c|c|}
\hline CAUSES & FREQUENCY \\
\hline Acute gastroenteritis & 34 \\
\hline $\begin{array}{c}\text { Hepatic causes (liver } \\
\text { cirrhosis, HRS, alcoholic liver } \\
\text { disease) }\end{array}$ & 15 \\
\hline $\begin{array}{l}\text { Cardiac causes (ccf, } \\
\text { cardiogenic shock) }\end{array}$ & 15 \\
\hline $\begin{array}{l}\text { Infective causes (malaria, } \\
\text { dengue, ARDS, pneumonia, } \\
\text { puereralsepsis, septicemia, } \\
\text { septic shock, viral hepatitis) }\end{array}$ & 27 \\
\hline
\end{tabular}

Most common cause of Pre-Renal Acute Kidney Injury in this study was Acute gastroenteritis (AGE) followed by infections. Dehydration was seen in all acute gastroenteritis related Acute Kidney Injury patients.

\section{TABLE SHOWING CAUSES INTRINSIC ACUTE KIDNEY INJURY}

\begin{tabular}{cc} 
Table 3: & \\
\hline CAUSES & FREQUENCY \\
\hline Bite (unknown+snake) & 32 \\
Poisoning (copper sulfate, & 15 \\
paraquat, herbicidal, unknown) & \\
Drugs (nsaid's, steroid) & 10 \\
Multiple organ dysfunction syndrome & 11 \\
Other(pre-eclampsia,dic, pyelonephritis) & 3 \\
\hline
\end{tabular}

Most common cause of renal Acute Kidney Injury in this study was snake bite and unknown bite followed by poisoning in this study. Among the 15 cases of poisoning four of them was paraquat poisoning.

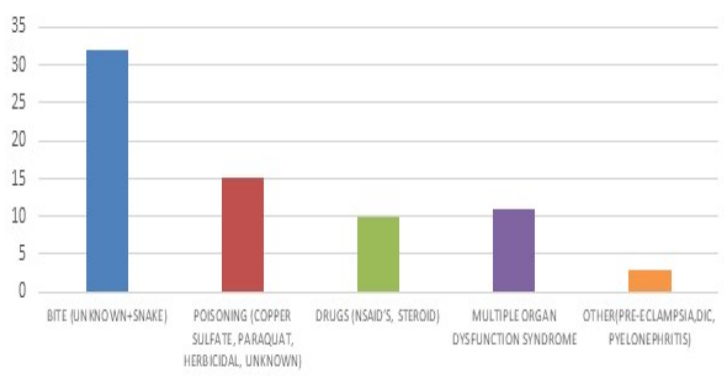

Figure 2: Causes of renal AKI

Table 4: Causes post-renal acute kidney injury

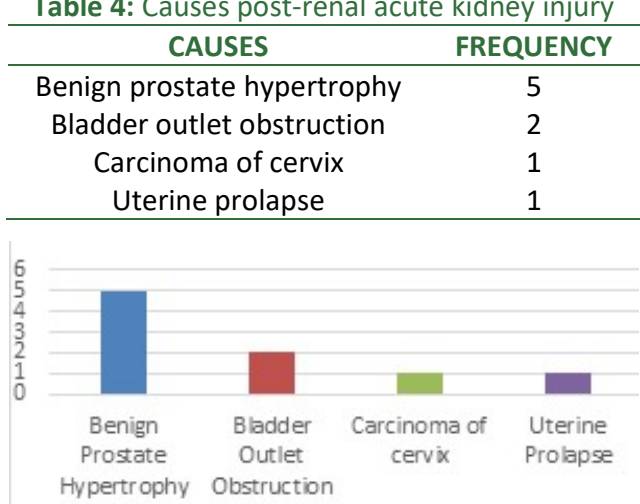

Figure 3: Causes of post renal AKI
Most common cause of post-renal Acute Kidney Injury was Benign Prostate Hypertrophy (BPH) in this study that was due to old age male patients were more.

\section{TYPE OF RENAL FAILURE}

In this study out of 170 patients, 91 (53.5\%) patients had Pre-Renal while $70(41.2 \%)$ patients had Intrinsic type of Renal Failure and only 9 (5.3\%) patient had Post Renal type of Renal Failure.

Table 5: Type of renal failure

\begin{tabular}{cc}
\hline TYPES OF RENAL FAILURE & NO OF PATIENTS \\
\hline PRE-RENAL & 91 \\
RENAL & 70 \\
POST RENAL & 9 \\
TOTAL & 170
\end{tabular}

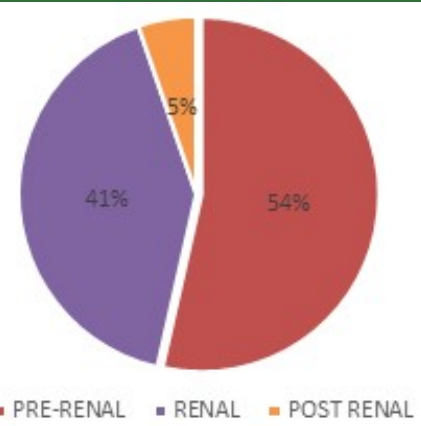

Figure 4: PERCENTAGE (\%)

As mentioned in various literature in this study also had Pre-Renal type of renal failure constitutes a major type of acute kidney injury.

\section{DISCUSSION}

We studied Acute Kidney Injury according to KDIGO definition with respect to incidence, different causes of Acute Kidney Injury and outcome in Medicine ward and Medicine ICU of our college and hospital from JANUARY 2018 to JUNE 2019.

Demographic variation

Out of 170 patients included in the study 112 were males and 58 were females with a mean age of 51.76 years with SD of 18.68, resulting in male: female ratio of $2: 1$ which is quite similar to study done by Patel $\mathrm{U} \mathrm{al}^{4}$, Rajesh $\mathrm{K}$ et al.. ${ }^{5}$, Eswarappa $\mathrm{M}$ et al.. ${ }^{6}$. The M:F 1.8:1 ratio of other developing countries, 1:1 ratio in developed countries. We observed a trend towards an increasing number of Acute Kidney Injury cases among male patients compared to female patients

In this study youngest age of 13 years and oldest age of 86 years. Compared with all admissions, patients with Acute Kidney Injury were found to be older and of male gender. It is also possible that still unknown genetic aspects may have influenced the incidence of Acute Kidney Injury in the male population. 


\section{CLINICAL FEAUTURES OF ACUTE KIDNEY INJURY}

We noticed that oliguria, edema and vomiting were most common presenting symptoms comprising of $44 \%, 45 \%$ and $34 \%$ respectively. This findings is compared with other studies done by Rajesh $\mathrm{K}$ et al.. 5 , which showed that oliguria and vomiting was seen in $82 \%$ and $90 \%$ of patients respectively, may be due to Diabetes and CKD cases included. Patel $\mathrm{U} \mathrm{al}^{4}$. study found that edema was seen in $28.5 \%$ of patients.

Fever is presentation in $33.5 \%$ of patients, similar to other study done by Patel $\mathrm{U} \mathrm{al}^{4}$, Soren B et al.. ${ }^{7}, 40 \%$ of patients had fever in Bhattacharya $\mathrm{P}$ et al. $.^{8}, 52 \%$ of patients had hypotension in Bernieh B et al.. ${ }^{9}$ study. Loose stools is presentation in $23.5 \%$ in this study is similar to Soren B et al.. ${ }^{7}$.

Out of jaundice $76.67 \%$ patients are only male due to alcoholic liver disease and associated complication. Hypotension is presentation in $37 \%$ of patient in this study is similar to Liano F et al. ${ }^{10}$ (32.8 \% patients). Similar to $28.6 \%$ of patients had hypotension in a study done by Rajesh K et al.. ${ }^{5}$.

\section{CAUSES OF ACUTE KIDNEY INJURY}

Hypovolemia due to diarrheal illness was the cause of Acute Kidney Injury $20 \%$ of patients in this study, which is similar to study done by Bhattacharya $\mathrm{P}$ et al. ${ }^{8}$ and Soren B et al. ${ }^{7}$ was $17.3 \%$ and $18 \%$ respectively. That is may be due to poor hygiene and lack of health education and most of these patients are inadequately managed at the primary level leading to more number of referrals to our tertiary center. Similarly, a significant decline in diarrhea related Acute Kidney Injury has been also reported from India by Prakash J et al.. ${ }^{11}$. In the this study $18.8 \%$ of patients had Acute Kidney Injury due to renal cause due to snake bite this is because the study was conducted in snake prevalent zone. Next Sepsis remains one of the major contributors of Acute Kidney Injury worldwide. In this study infective causes of Acute Kidney Injury were seen in $15.8 \%$ of Acute Kidney Injury population. This is consistent with Rajesh $\mathrm{K}$ et al..5. Tropical infections including Dengue (1.76\%) and malaria (1.17\%) were also responsible for Acute Kidney Injury cases in this study. early diagnosis and adequate treatment was taken by patients so incidence of tropical infections induced Acute Kidney Injury is lower in our area. In this study other common etiology is poisoning (8.8\%) similar to Patel U et al.. ${ }^{4}$ study. Out of poisoning unknown compound poisoning is more common in this study. Consumption of poisons (like Corrosives, Cuso4, Paraquat, Rodenticide, Pesticide, Plant poison, Alcohol, Hair dye etc.) was a cause of Acute Kidney Injury in 14 patients in this study. Cardiac causes such as myocardial infarction, heart block, CCF, ARDS with respiratory failure were the causes of Acute
Kidney Injury in $8.2 \%$ of our patients similar to study done by Vikrant $\mathrm{S}$ et al.. ${ }^{12}$. In the current study, $5.8 \%$ of patients developed Acute Kidney Injury secondary to nephrotoxic drugs. The variety of drugs associated with Acute Kidney Injury in this study show consistence with the changing epidemiology of drug-related Acute Kidney Injury observed by Prakash $\mathrm{J}$ et al.. ${ }^{11}$ and Vikrant $\mathrm{S}$ et al.. ${ }^{12}$. Nephrotoxic drugs in this study included NSAIDs like diclofenac sodium, steroids and angiotensin receptor blockers. Obstructive uropathy was secondary to renal or ureteric or bladder calculi, carcinoma cervix, uterine prolapse and prostatic enlargement. Acute Kidney Injury is one of the most challenging complications of pregnancy in developing countries and is frequently related to suboptimal antenatal care, home delivery in rural areas, and unsafe abortions conducted by unqualified personnel or using insecure medicines.

\section{CONCLUSION}

From this study, we observed that most of the patients affected by Acute Kidney Injury were in the age group of more than 40 years in our hospital. Edema, Oliguria and vomiting were common presentation of Acute Kidney Injury in this study due to late referral of patients from other hospitals, no awareness and lack of health education. Highest incidence of Acute Kidney Injury was attributed to medical disorders consisting of mainly septicemia, acute gastroenteritis, multiple organ dysfunction syndrome, snake bite and Nephrotoxic drugs. The major risk factors affecting prognosis of the patients were presence of multi organ failure, high baseline serum creatinine level and complications developed during the course of illness. Finally to conclude Timely diagnosis and the management of this disease condition confer a favourable prognosis to the patient. The progression of Acute Kidney Injury leads to increased hospital mortality and increased length of hospital stays that might prove wastage of limited resources in a setting like India. Further studies on large scale are required to prove its significance.

\section{REFERENCES}

1. Jameson, Fauci, kasper, Hauser, Longo, Loscalzo Harrison's principles of Internal Medicine 20th edition;2018; volume 2:p 2099-2111

2. Khwaja A. KDIGO clinical practice guidelines for acute kidney injury. Vol. 120, Nephron - Clinical Practice. 2012. p. $179-84$.

3. KDIGO Board Members. Kidney Int Suppl. 2012;2(1):3.

4. Patel U, Pasari A, Balwani M, Bhawane A, Tolani P, Acharya S. Clinical profile of acute kidney injury in a tertiary care center in the Tropical Region. J Integr Nephrol Androl. 2018;5(4):130.

5. Rajesh K, Rajak M, Seshagirirao Y. Clinical manifestations of Acute kidney injury: A Prospective Observational Study. 2017;16(8):22-8. 
6. Eswarappa M, Gireesh MS, Ravi V, Kumar D, Dev G. Spectrum of acute kidney injury in critically ill patients: A single center study from South India. Indian J Nephrol. 2014;24(5):280-5.

7. Soren B, Papareddy A, Kommareddy S, Meriga R, Midathala N, Sarikonda G. Clinical profile of acute kidney injury in patients admitted to medical wards in a tertiary care setting. Int J Med Sci Public Heal. 2018;8(0):1.

8. Bhattacharya P, Roy A, Jamil M, Barman B, Murti S, Marak P. Clinical profile and determinants of short-term outcome of acute kidney injury: A hospital-based prospective study from Northeastern India. J Lab Physicians. 2019;11(1):5.

9. Bernieh B, Al Hacute kidney injurym M, Boobes $\mathrm{Y}$, Siemkovics E, El Jack H. Outcome and predictive factors of acute renal failure in the intensive care unit. In: Transplantation Proceedings. 2004. p. 1784-7.

10. Liaño F, Pascual J, Gámez C, Gallego A, Bajo MA, Sicilia LS, et al.. Epidemiology of acute renal failure: A prospective, multicenter, community-based study. Kidney Int. 1996;50(3):811-8.

11. Prakash J, Singh TB, Ghosh B, Malhotra V, Rathore SS, Vohra R, et al.. Changing epidemiology of communityacquired acute kidney injury in developing countries: Analysis of 2405 cases in 26 years from eastern India. Vol. 6, Clinical Kidney Journal. 2013. p. 150-5.

12. Vikrant S, Gupta D, Singh M. Epidemiology and outcome of acute kidney injury from a tertiary care hospital in India. Saudi J Kidney Dis Transpl. 2018;29(4):956-66.

\section{Source of Support: None Declared}

\section{Policy for Articles with Open Access:}

Authors who publish with MedPulse International Journal of Medicine, Print ISSN: 2550-7583, Online ISSN: 2636-4751 agree to the following terms: Authors retain copyright and grant the journal right of first publication with the work simultaneously licensed under a Creative Commons Attribution License that allows others to share the work with an acknowledgement of the work's authorship and initial publication in this journal. Authors are permitted and encouraged to post links to their work online (e.g., in institutional repositories or on their website) prior to and during the submission process, as it can lead to productive exchanges, as well as earlier and greater citation of published work. 